\title{
Importance of esophageal pH monitoring and manometry in indicating surgical treatment of gastroesophageal reflux disease
}

\author{
José Roberto Alves ${ }^{1 *}$ (1)
}

\section{SUMMARY}

OBJECTIVE: To demonstrate the need of performing esophageal pH monitoring and manometry in patients with clinical suspicion of Gastroesophageal reflux disease, as more accurate and practical complementary exams in the indication of surgical treatment.

METHODS: A systematic review was carried out in the PubMed/Medline database, based on the recommendations of the PRISMA (Preferred Reporting Items for Systematic Reviews and Meta-Analyses) protocol, selecting studies in humans, published in Portuguese, Spanish, and English, from January 1, 2009 to August 5, 2020. The following descriptors were used: "reflux gastroesophageal" AND "surgery" AND "surgical treatment" AND "esophageal manometry" OR "pH monitoring". After that, retrospective or prospective observational studies with a sample of less than 100 individuals, or with limited access, reports or case series, review articles, letters, comments, or book chapters were excluded. To facilitate the application of the exclusion criteria, the Rayyan management base was used. RESULTS: Out of the 676 studies found, 19 valid and eligible studies were selected to make inferences.

CONCLUSIONS: Based on the best evidence, currently, considering national particularities, performing a 24-hour esophageal pH monitoring and esophageal manometry for all patients undergoing anti-reflux surgery.

KEYWORDS: Gastroesophageal reflux. Laryngopharyngeal reflux. Diagnosis. Esophageal pH monitoring. Manometry.

\section{INTRODUCTION}

Gastroesophageal reflux refers to the retrograde passage of stomach contents into the esophagus. In the presence of associated symptoms and/or lesions on the esophageal mucosa (esophagitis), it becomes a pathologic condition called gastroesophageal reflux disease (GERD) $)^{1,2}$. The most important protective mechanisms from gastric reflux include: (1) the functional integrity of the esophageal body and lower esophageal sphincter, (2) constant swallowing of saliva and (3) gravity ${ }^{1}$.

Being one of the most common diseases in practice, GERD is a highly prevalent disease in all age groups and in both sexes, affecting up to $20 \%$ of the entire western world population ${ }^{3,4}$.

The first therapeutic approach to GERD is the use of proton pump inhibitors (PPI) and anti-reflux behavioral measures.
In refractory (i.e., those with persistent symptoms for more than once a week after at least two months of full-dose PPI therapy) ${ }^{5}$ or complicated cases (i.e., those with recurrent esophagitis, stenosis, or Barrett's esophagus $>3 \mathrm{~cm}$ ), or patient refusal to prolonged PPI therapy, anti-reflux surgery, such as fundoplication with or without hiatoplasty, may be indicated ${ }^{6}$.

Establishing a correct early diagnosis and identifying the conditions that may prevent a good response to medical management in GERD patients is essential. Currently, the diagnosis of GERD may be provided with endoscopy and 24-hour $\mathrm{pH}$ monitoring ( $\mathrm{pH}-24 \mathrm{~h})$. Endoscopic findings suggestive of GERD include severe esophagitis (Los Angeles C or D), Barrett's esophagus (confirmed by histological findings), and peptic stenosis. In addition, $\mathrm{pH}-24 \mathrm{~h}$ results showing an acid exposure time

\footnotetext{
'Universidade Federal de Santa Catarina, Curso de Medicina, Departamento de Cirurgia - Florianópolis (SC), Brasil.

*Corresponding author: joserobertoalves1980@gmail.com

Conflicts of interest: the authors declare there is no conflict of interests. Funding: none.

Received on September 10, 2020. Accepted on September 10, 2020.
} 
(AET) greater than $6 \%$ is consistent with pathologic reflux 3 . AET refers to the percentage of time that the esophageal mucosa is exposed to acid reflux at $\mathrm{pH}<4^{3}$. At AETs between 4 to 6\%, however, the Lyon Consensus recommends that other adjuvant parameters should be considered to establish the diagnosis of pathologic reflux, such as the DeMeester Index or the identification of more than 80 refluxes in 24 hours $^{3}$.

For cases in which anti-reflux surgery is indicated, esophageal manometry is warranted to evaluate the presence of esophageal motility disorders before surgery, weigh the risks for complications (e.g., dysphagia, meteorism, recurrence of symptoms, etc.) and prognosticate on the expected results ${ }^{4,7}$.

Although $\mathrm{pH}-24 \mathrm{~h}$ and esophageal manometry should ideally be part of the pre-operative evaluation of all GERD patients, this is not the case in the daily medical practice in Brasil. This review aimed to demonstrate and justify, based on the best available evidence, the importance of requesting both $\mathrm{pH}-24 \mathrm{~h}$ and esophageal manometry for all GERD patients, especially for those eligible for surgical treatment.

\section{METHODS}

Based on the recommendations of the Preferred Reporting Items for Systematic Reviews and Meta-Analyses (PRISMA) ${ }^{8}$ protocol, a systematic review of the selected medical studies on humans published in the PubMed/Medline database from January 1, 2009 to August 5, 2020 was performed. The following key terms and Boolean operators were used for advanced search: (reflux gastroesophageal [Title]) AND (surgery [Title/ Abstract]) AND (surgical treatment [Title/Abstract]) AND (esophageal manometry [Title/Abstract]) OR ( $\mathrm{pH}$ monitoring [Title/Abstract]). Selection of studies used to produce the inferences presented in this review was based on the following inclusion and exclusion criteria:

\section{Inclusion criteria}

1. Studies written in Portuguese, Spanish, and English published during the aforementioned period.

2. Studies conducted on humans aged over 18 years old.

3. A globally accepted consensus was exceptionally included in this review to facilitate description of fundamental concepts related to GERD diagnosis ${ }^{3}$.

\section{Exclusion criteria}

1. Studies available only as abstracts (limited access).

2. Report type study or case series, review articles with or without systematization, letters, comments, or book chapters.

3. Retrospective observational studies.
4. Prospective study, but with a sample size with less than 100 participants.

5. Duplicate or triplicate studies. In these cases, only one of the studies was kept for inferences, the other replicate studies were excluded.

To facilitate the use of the exclusion criteria above and help eliminate duplicate or triplicate studies, the Rayyan management database was used (Qatar Computing Research Foundation Institute, Doha, Qatar), available at https://rayyan.qcri.org9?

\section{RESULTS}

Of the 676 studies found through the aforementioned search engine, 19 valid and eligible studies were selected based on pre-established inclusion and exclusion criteria to foster future inferences. The flowchart describes the entire search and selection process (Figure 1).

Although there are intrinsic methodological limitations in most of the 19 eligible studies, these did not hinder the analysis of the inferences drawn in this review (Table 1).

\section{DISCUSSION}

Currently, the $\mathrm{pH}-24 \mathrm{~h}$ is considered the gold standard for the diagnosis of GERD ${ }^{2,4,10}$. Although the identification of histologic changes (i.e., dilatation of the intercellular spaces of the esophageal epithelium and expression of TRPV1 receptors) may confirm the diagnosis of GERD ${ }^{11}$, its use has been questionable in clinical practice due to limited data on literature. This reinforces the value of $\mathrm{pH}-24 \mathrm{~h}$ in medical practice (Figure $2 \mathrm{~A}$ ).

Although the $\mathrm{pH}-24 \mathrm{~h}$ may be improved with impedance reflux monitoring by increasing the understanding of the pathophysiology and etiology of GERD to establish differential diagnoses ${ }^{12}$, the use of both tests may not be feasible considering the costs and accessibility of the examinations in most Brazilian territory. The use of $\mathrm{pH}-24 \mathrm{~h}$ alone should be considered a mandatory examination for the precise diagnosis of GERD and in the preparation of patients for surgical treatment, for reasons described as follows:

The use of $\mathrm{pH}-24 \mathrm{~h}$ may avoid the issues concerning the use of PPIs in both diagnostics and treatment. High diagnostic errors (error rates: 30 to $51 \%$ of cases) related to the use of a low specificity therapeutic trial of PPI for 14 days implies that it may not be reliable to prove a pathologic acid reflux in the esophagus $^{10,12,13}$. Furthermore, the prolonged and inappropriate use of PPIs in cases of misdiagnosis may cause adverse effects (e.g., osteoporosis) and unnecessary expenses to patients $s^{5,10,13-15}$. This may be apparent in cases of functional pyrosis, in which placebo 
effects related to the use of drugs, especially PPI, have been reported. In addition, this may also be evident in patients with non-specific laryngeal changes in videolaryngoscopy, or in those with chronic cough (eight weeks more) ${ }^{2,11,14}$. Although some changes in the laryngeal mucosa (e.g., erythema and edema of the posterior larynx) can occur in GERD, these changes are not diagnostic ${ }^{2}$.

Moreover, the $\mathrm{pH}-24 \mathrm{~h}$ with two sensors can establish an accurate diagnosis of laryngeal or superior reflux through the superior sensor ${ }^{15}$. This may further classify the type of gastroesophageal reflux (a) based on the affected region: (1) isolated proximal, (2) isolated distal, (3) proximal and distal reflux; and (b) based on patient position: (1) predominantly supine, (2) orthostatic or (3) mixed reflux, for better treatment planning ${ }^{1}$.

In addition, the $\mathrm{pH}-24 \mathrm{~h}$ may predict the most severe forms of esophagitis, as evidenced by the higher frequency of reflux episodes $>5 \mathrm{~min}$, higher AET, and higher DeMeester score ${ }^{10}$.

Consequently, the high negative correlation between clinical presentation and presence of pathologic acid reflux, especially in patients with anxiety disorders, may be further evaluated ${ }^{2,23}$.

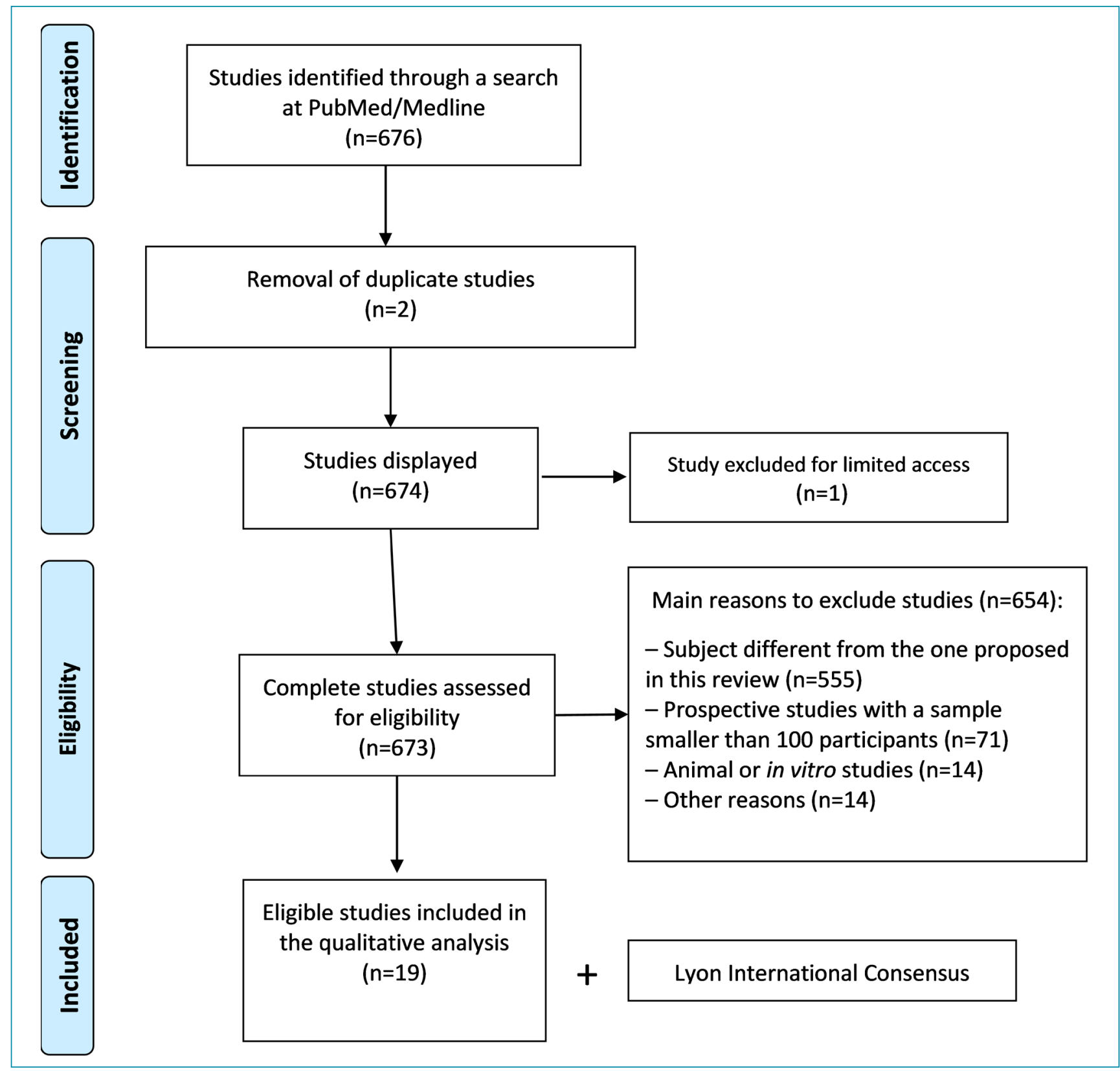

Figure 1. Flowchart showing the search and selection process of eligible studies. The Lyon International Consensus ${ }^{3}$ is the current diagnostic criteria established for Gastroesophageal reflux disease. 
Table 1. Limitations of the 19 eligible studies identified by year of publication, type of study, presence of randomization, and sample size.

\begin{tabular}{|c|c|c|c|c|c|}
\hline Author & $\begin{array}{c}\text { Year of } \\
\text { publication }\end{array}$ & $\begin{array}{l}\text { Type of } \\
\text { study }\end{array}$ & Randomization & $\begin{array}{c}\text { Sample } \\
\text { (participants) }\end{array}$ & Study limitations \\
\hline Ozin et al. ${ }^{1}$ & 2009 & Prospective & no & 550 & No description. \\
\hline Rybka et al. ${ }^{2}$ & 2014 & Prospective & no & 204 & $\begin{array}{l}\text { The specificity and accuracy } \\
\text { of the diagnosis with } \mathrm{pH}-24 \mathrm{~h} \\
\text { could not be evaluated as } \\
\text { any reference method for the } \\
\text { diagnosis of GERD. Monitoring } \\
\text { of pH was performed during } \\
\text { hospital stay, which may have } \\
\text { affected the results. } \\
\text { No cough monitor was used, } \\
\text { despite patients having } \\
\text { subjective episodes of cough. } \\
\text { The lack of manometry } \\
\text { resulted in the inaccurate } \\
\text { placement of the pH } \\
\text { electrodes, which may result } \\
\text { in overdiagnosis of a reflux } \\
\text { episode. }\end{array}$ \\
\hline Oor et al. ${ }^{4}$ & 2018 & Prospective & yes & 309 & $\begin{array}{l}\text { Data on the likelihood of } \\
\text { symptom association from } \\
\text { routine pH studies were not } \\
\text { available and could not be } \\
\text { included. }\end{array}$ \\
\hline Hamdy et al. ${ }^{5}$ & 2014 & Prospective & no & 370 & No description. \\
\hline Morrow et al. ${ }^{6}$ & 2014 & Prospective & no & 215 & $\begin{array}{l}\text { Observational study that did } \\
\text { not include a comparison with } \\
\text { a control group of patients in } \\
\text { drug treatment. Furthermore, } \\
\text { not all pre- and post-operative } \\
\text { endoscopic biopsies of } \\
\text { patients were performed } \\
\text { and analyzed by the same } \\
\text { endoscopist and pathologist. }\end{array}$ \\
\hline $\begin{array}{l}\text { Humphries } \\
\text { et al. }{ }^{7}\end{array}$ & 2013 & $\begin{array}{l}\text { Prospective } \\
\text { based on } \\
\text { retrospective } \\
\text { series }\end{array}$ & no & 786 & No description. \\
\hline Chan et al. ${ }^{10}$ & 2010 & Prospective & no & 374 & $\begin{array}{l}\text { All patients were referred by } \\
\text { their respective physicians } \\
\text { for pH-24h and manometry. } \\
\text { This may result in selection } \\
\text { bias that could overrepresent } \\
\text { the severe cases of GERD } \\
\text { and atypical GERD symptoms } \\
\text { without GERD pathology. } \\
\text { In addition, a single clinical } \\
\text { questionnaire was used to } \\
\text { evaluate GERD. }\end{array}$ \\
\hline
\end{tabular}

Continue... 
Table 1. Continuation.

\begin{tabular}{|c|c|c|c|c|c|}
\hline Author & $\begin{array}{c}\text { Year of } \\
\text { publication }\end{array}$ & $\begin{array}{l}\text { Type of } \\
\text { study }\end{array}$ & Randomization & $\begin{array}{c}\text { Sample } \\
\text { (participants) }\end{array}$ & Study limitations \\
\hline Bortoli et al. ${ }^{11}$ & 2014 & Prospective & no & 312 & $\begin{array}{l}\text { There is a possibility that } \\
\text { some GERD patients were } \\
\text { incorrectly classified due to: } \\
\text { (1) limited } 24 \mathrm{~h} \text { evaluation } \\
\text { period with impedance pH } \\
\text { monitoring; (2) presence of } \\
\text { unexplainable causes for } \\
\text { good response to treatment } \\
\text { with PPl; and (3) chance } \\
\text { of false negative results in } \\
\text { GERD patients with erosive } \\
\text { esophagitis or Barrett's } \\
\text { esophagus. }\end{array}$ \\
\hline Masiak et al. ${ }^{12}$ & 2011 & Prospective & no & 234 & No description. \\
\hline Bello et al. ${ }^{13}$ & 2013 & Prospective & no & 134 & $\begin{array}{l}\text { Endoscopy was performed } \\
\text { only in } 46 \% \text { of patients (risk } \\
\text { of type I error). Moreover, the } \\
\text { esophageal pH evaluation } \\
\text { period was limited to only } \\
\text { acid reflux within } 24 \text { hours. } \\
\text { Furthermore, most patients } \\
\text { were referred out of the } \\
\text { University of Chicago system, } \\
\text { and patients who had not } \\
\text { undergone surgery could not } \\
\text { be followed up. }\end{array}$ \\
\hline Pugliese et al. ${ }^{14}$ & 2016 & Prospective & no & 184 & No description. \\
\hline Friedman et al. ${ }^{15}$ & 2012 & $\begin{array}{l}\text { Prospective } \\
\text { based on } \\
\text { retrospective } \\
\quad \text { series }\end{array}$ & no & 163 & $\begin{array}{l}\text { The possible interference } \\
\text { of years of smoking is } \\
\text { disregarded as to development } \\
\text { of symptom s. }\end{array}$ \\
\hline Hatlebakk et al. ${ }^{16}$ & 2016 & Prospective & yes & 267 & No description. \\
\hline Jasper et al. ${ }^{17}$ & 2017 & Prospective & no & 517 & $\begin{array}{l}\text { None of the healthy } \\
\text { control participants and } \\
\text { not all patients completed } \\
\text { the reflux studies with } \\
\text { impedance pH monitoring. } \\
\text { In addition, the study was } \\
\text { not population-based. } \\
\text { Patients who did not adhere } \\
\text { to the measurement pattern } \\
\text { in manometry (i.e., repetitive } \\
\text { swallowing at intervals } \\
\text { of less than } 20 \text { seconds) } \\
\text { were excluded. }\end{array}$ \\
\hline $\begin{array}{l}\text { Patcharatrakul } \\
\text { et al. }{ }^{18}\end{array}$ & 2014 & Prospective & no & 236 & No description. \\
\hline $\begin{array}{l}\text { Ciriza-de-los-Ríos } \\
\text { et al. } .^{19}\end{array}$ & 2014 & Prospective & no & 115 & $\begin{array}{l}\text { Sample has low number } \\
\text { of patients with type III } \\
\text { esophagogastric junction. }\end{array}$ \\
\hline
\end{tabular}


Table 1. Continuation.

\begin{tabular}{|c|c|c|c|c|c|}
\hline Author & $\begin{array}{c}\text { Year of } \\
\text { publication }\end{array}$ & $\begin{array}{l}\text { Type of } \\
\text { study }\end{array}$ & Randomization & $\begin{array}{c}\text { Sample } \\
\text { (participants) }\end{array}$ & Study limitations \\
\hline Fornari et al. ${ }^{20}$ & 2011 & Prospective & no & 332 & $\begin{array}{l}\text { Conventional manometry was } \\
\text { used, and only the presence } \\
\text { of acid reflux was evaluated. } \\
\text { Waist circumference of patients } \\
\text { was not measured. }\end{array}$ \\
\hline Tolone et al. ${ }^{21}$ & 2015 & Prospective & no & 130 & $\begin{array}{l}\text { The evaluation of the } \\
\text { esophagogastric junction } \\
\text { contractile integral (EGJ- } \\
\text { CI) was performed at the } \\
\text { beginning of the recording } \\
\text { period at rest, and the value } \\
\text { may be impaired. } \\
\text { A control group was not } \\
\text { included. }\end{array}$ \\
\hline Broeders et al. ${ }^{22}$ & 2011 & $\begin{array}{l}\text { Prospective } \\
\text { (retrospective } \\
\text { analysis of } \\
\text { prospective } \\
\text { series) }\end{array}$ & no & 177 & No description. \\
\hline $\begin{array}{l}\text { Laurino Neto } \\
\text { et al. }{ }^{23}\end{array}$ & 2019 & Prospective & no & 245 & $\begin{array}{c}\text { The questionnaire used was } \\
\text { not specific for digestive } \\
\text { disease and did not include } \\
\text { analysis of depression. } \\
\text { Furthermore, the availability of } \\
\text { endoscopic data was limited. }\end{array}$ \\
\hline
\end{tabular}

GERD: gastroesophageal reflux disease; PPI: proton pump inhibitors.

Markedly, it may also eliminate a false GERD diagnosis from endoscopy. According to the Lyon Consensus ${ }^{3}$, mild esophagitis seen on upper gastrointestinal endoscopy cannot be considered a diagnostic criterion for GERD due to the possibility of error in the subjective visual impression of the endoscopist (e.g., might be confused with drug-induced esophagitis caused by the use of tetracycline or other medications) ${ }^{13}$.

Furthermore, the $\mathrm{pH}-24 \mathrm{~h}$ has a role in diagnosing cases that do not require surgical treatment, such as functional pyrosis (i.e., absence of esophagitis in upper GI endoscopy associated with normal AET and negative symptoms for reflux), hypersensitive esophagus (i.e., absence of esophagitis in upper GI endoscopy associated with normal AET and positive symptoms for reflux), and irritable bowel syndrome $e^{11,13,14}$. It is worth noting that cases of hypersensitive esophagus may have clinical presentations even with normal AET values ${ }^{11}$.

More importantly, it may identify patients who may require higher PPI doses or those who may benefit more from surgery. The comparison between anti-reflux surgery and PPI treatment (esomeprazole 20 or $40 \mathrm{mg} /$ day) have shown that although both treatments significantly reduced the total $24 \mathrm{~h}$
AET in the distal esophagus, acid exposure is lower in patients undergoing anti-reflux surgery (almost eliminating reflux $)^{16}$. However, patients with supine-type pathologic reflux warrants higher PPI doses (esomeprazole $40 \mathrm{mg} /$ day) divided into two daily doses to improve control of nighttime reflux and effectively reduce $\mathrm{AET}^{16}$.

Finally, even in post-surgical GERD patients with recurrence of symptoms, there is an advantage in using $\mathrm{pH}-24 \mathrm{~h}$ to confirm that the symptoms are related to the pathologic acid reflux ${ }^{4,10}$. Nevertheless, evidence of acid reflux in $\mathrm{pH}-24 \mathrm{~h}$ after fundoplication should not be considered an exclusive indication for revision surgery, since patients have a reduced ability to perceive reflux after fundoplication ${ }^{4}$.

Esophageal manometry plays a key role in the study of esophageal motility to confirm other differential diagnoses of GERD, especially achalasia (which can present with pyrosis in $40 \%$ of cases) and diffuse esophageal spasm ${ }^{1,13,17}$. Furthermore, this can also establish the optimal surgical technique for GERD and determine the most accurate position for the $\mathrm{pH}-24 \mathrm{~h}$ catheter sensor ${ }^{13}$. A study by Belo et al. ${ }^{13}$ have shown that up to $3 \%$ of patients initially diagnosed with GERD and referred for surgery 
were identified to have achalasia in esophageal manometry, illustrating that this test is essential to avoid iatrogenic effects.

Esophageal manometry has an undeniable importance to detect esophageal dysmotility in GERD patients. Roughly 25 to $48 \%$ of these patients may present with esophageal motility disorder, and the prevalence of dysmotility increases according to the severity of esophagitis due to the pathologic reflux ${ }^{18}$. Ineffective esophageal motility (defined by an esophageal body contraction amplitude $<30 \mathrm{mmHg}$ and/or non-transmission of $30 \%$ or more wet swallowing to the distal esophagus) is the most common esophageal dysmotility in GERD patients (20 to $50 \%$ of cases), followed by nutcracker esophagus and diffuse esophageal spasm ${ }^{1,18}$. The presence of esophageal dysmotility can impair the esophageal clearance of gastric content, thereby increasing the occurrence of superior reflux ${ }^{18}$. Esophageal body hypomotility, characterized by a decreased mean range of contractions (less than or equal to $30 \mathrm{mmHg}$ ) in the esophageal segment, is also a frequent finding in patients with severe esophagitis due to GERD ${ }^{1}$.

In addition, esophageal manometry provides a detailed evaluation of the esophagogastric junction, helps discover etiologic factors, and estimates GERD severity.

Moreover, it can also identify and adequately classify esophageal hiatus hernias, which are often misdiagnosed due to the incorrect interpretation of subjective endoscopic findings and failure in considering the physiologic movement of the esophagogastric junction ${ }^{17,19}$. The evaluation of esophageal junction morphology and contractility could identify patients with decreased lower esophageal sphincter pressure (more common in patients with isolated distal esophageal reflux) who may potentially respond better to surgery ${ }^{1,17}$. This may also estimate the esophageal length within the abdominal cavity, as a decreased length favors greater acid exposure ${ }^{17}$.

Moreover, aging, elevated body-mass index (BMI), and central obesity are risk factors for the development of esophagogastric junction disorders (i.e., diseases between the diaphragmatic crura and the lower esophageal sphincter), decreased resting pressure, and shorter length of the abdominal esophagus $^{19}$. Furthermore, patients with type II and III esophagogastric junction (hiatal hernia) had higher acid exposure ${ }^{19}$. Despite this, the study by Fornari et al. ${ }^{20}$ have shown that obese patients $\left(\mathrm{BMI}=\right.$ or $\left.>30 \mathrm{~kg} / \mathrm{m}^{2}\right)$ had stronger esophageal peristalsis, lower esophageal sphincter pressure, and higher AET, regardless of the presence of GERD.

When accessible, the possibility of performing high-resolution esophageal manometry ( $>8$ sensors) could improve the evaluation of the esophagogastric junction by determining the esophagogastric junction contractility index (Figure 2B). At values below $13 \mathrm{mmHg} . \mathrm{cm}$, there is a higher occurrence of reflux episodes and higher AET in the esophagus, which could be

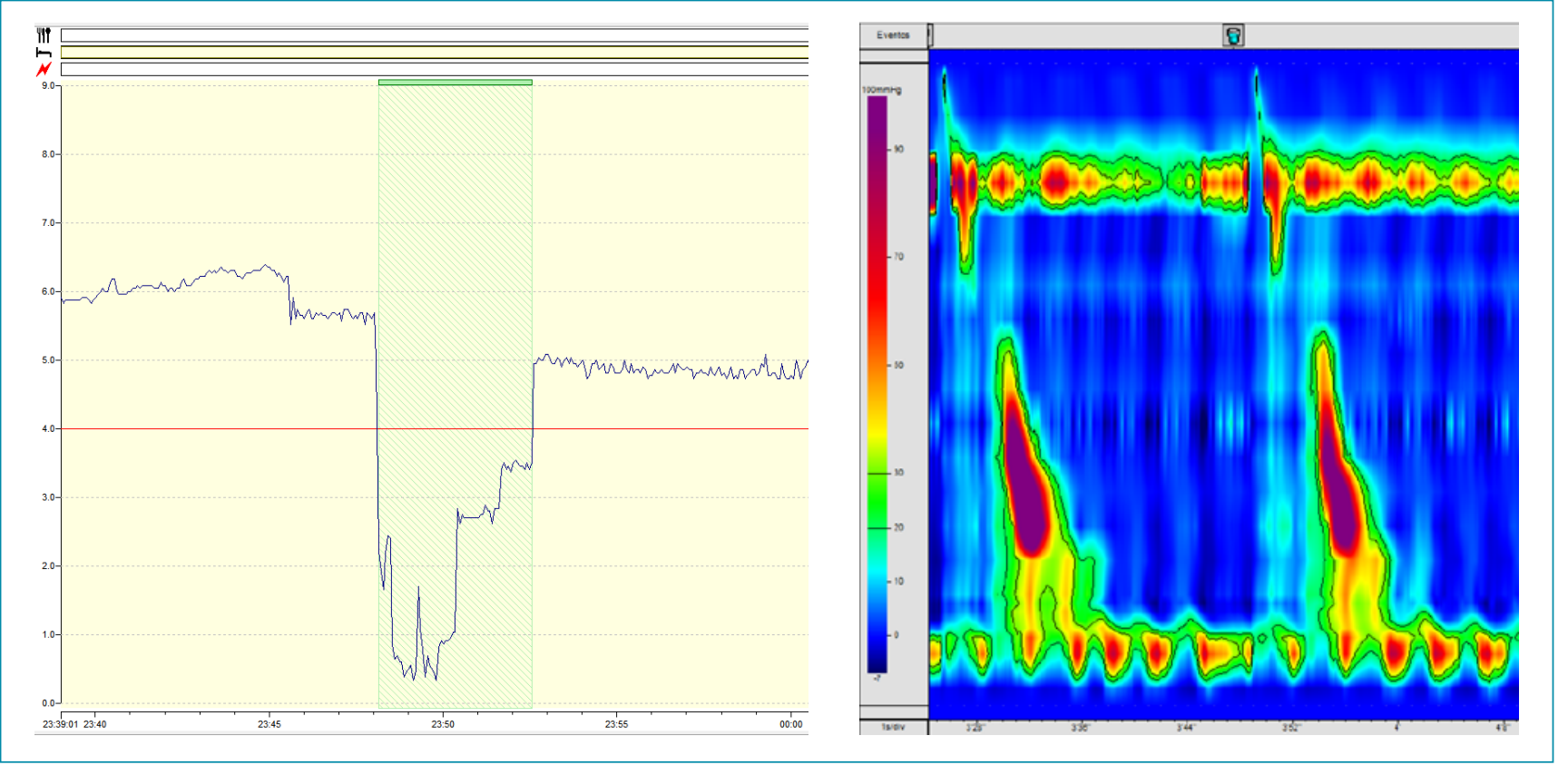

Figure 2. (A) A section of a pH-24h graph (left) of a patient in dorsal decubitus position (supine position) presenting with reflux $(\mathrm{pH}<4)$, lasting approximately 4.5 minutes (area highlighted in the green figure). (B) A section of a high-resolution manometry graph (right) presenting the complete evaluation of wet swallowing and the sequential contraction of the upper esophageal sphincter, body, and lower esophageal sphincter (PH-metry and manometry system software, Version 1.264b. ALACER Biomédica, São Paulo, Brasil). 
crucial to plan the degree of fundoplication valve continence ${ }^{21}$. At values, higher than $47 \mathrm{mmHg} . \mathrm{cm}$, reflux episodes are rare $^{21}$.

Furthermore, esophageal manometry plays an important role in understanding the pathophysiology of clinical manifestations related to GERD. For example, it has been shown that acid regurgitation is associated with pathologic gastroesophageal acid reflux with no significant effect on esophageal motility, suggesting that esophageal contraction should generally not occur during regurgitation ${ }^{18}$. However, chronic cough, voice hoarseness, and dysphagia have been associated with esophageal motility disorders in patients with abnormal exposure to acid in the esophagus ${ }^{18}$.

Although it is not the focus of this review, the use of contrast-enhanced esophagoduodenal radiography in the pre-operative evaluation of GERD patients is worth mentioning. Radiography may provide crucial esophageal anatomy to evaluate the esophageal hiatus hernias and identify Schatzki's ring and peptic stenosis. However, it has a low sensitivity (40\%) and specificity (85\%) for the diagnosis of GERD, since it rarely shows the presence of gastric content reflux into the esophagus. Moreover, the presence of reflux is not necessarily associated with the GERD as identified at $\mathrm{pH}-24 \mathrm{~h}^{13}$. Therefore, a contrast-enhanced esophagoduodenal X-ray should not be used to diagnose GERD and should not replace pre-operative $\mathrm{pH}-24 \mathrm{~h}$ and esophageal manometry ${ }^{13}$.

Clearly, the surgical treatment for GERD aims to provide an anti-reflux barrier by increasing the length of a new pressure zone at the level of the esophagogastric junction. However, it is necessary to pay attention to some aspects when evaluating the results and post-operative follow-up of patients ${ }^{6}$. To predict the outcome of anti-reflux surgery in GERD patients, patients with inadequate pre-operative esophageal peristalsis and excessive esophageal exposure to acid, especially in the supine position, must be closely monitored ${ }^{22}$. Patients who had both variables before surgery had a ten-fold increase in the incidence of surgical treatment failure regarding the definitive control of pathologic acid exposure compared to patients without the two pre-operative factors ${ }^{22}$. These variables are better predictors of post-operative outcomes than other factors such as demographic data, clinical manifestations (pyrosis and regurgitation), age, sex, body mass index, hiatal hernia size, presence of esophagitis, and lower esophageal sphincter pressure ${ }^{22}$.

Finally, although anti-reflux surgery is associated with a percentage of epithelial regression in patients with Barrett's esophagus (mostly of the short type), $7 \%$ of cases progressed with the onset of dysplasia or adenocarcinoma. This reinforces the need for regular endoscopic follow-up even after the anti-reflux surgery, especially in those with anaplastic risk factors (e.g., Barrett's esophagus with minimal progression for ten years, with length $>3 \mathrm{~cm}$, or when associated with esophagitis) ${ }^{6}$.

\section{CONCLUSIONS}

Based on the current best evidence and national particularities, all patients indicated for anti-reflux surgery are recommended to undergo both 24-hour $\mathrm{pH}$ monitoring and esophageal manometry to avoid diagnostic errors and improve surgical treatment planning.

\section{ACKNOWLEDGMENTS}

The author would like to thank Dr. Ricardo Guilherme Viebig for his constant support to improve the author's knowledge in the area of digestive motility and contributions to make the writing of this article clearer.

\section{REFERENCES}

1. Ozin Y, Dagli U, Kuran S, Sahin B. Manometric findings in patients with isolated distal gastroesophageal reflux. World J Gastroenterol. 2009;15(43):5461-4. https://doi.org/10.3748/ wjg. 15.5461

2. Rybka A, Malesa K, Radlińska O, Krakowiak K, Grabczak EM, Dąbrowska $\mathrm{M}$, et al. The utility of oesophageal $\mathrm{pH}$ monitoring in diagnosing gastroesophageal reflux disease-related chronic cough. Pneumonol Alergol Pol. 2014;82(6):489-94. https:// doi.org/10.5603/PiAP.2014.0065

3. Gyawali CP, Kahrilas PJ, Savarino E, Zerbib F, Mion F, Smout AJPM, et al. Modern diagnosis of GERD: the Lyon Consensus. Gut. 2018;67(7):1351-62. https://doi.org/10.1136/gutjnl2017-314722
4. Oor JE, Nieuwenhuijs VB, Devitt PG, Hazebroek EJ, Watson DI Outcome for patients with pathological esophageal acid exposure after laparoscopic fundoplication. Ann Surg. 2018;267(6):110511. https://doi.org/10.1136/10.1097/SLA.0000000000002276

5. Hamdy E, El Nakeeb A, Hamed H, El Hemaly M, ElHak NG. Outcome of laparoscopic Nissen fundoplication for gastroesophageal reflux disease in non-responders to proton pump inhibitors. J Gastrointest Surg. 2014;18(9):1557-62. https://doi.org/10.1007/s11605-014-2584-3

6. Morrow E, Buschyhead D, Wassenaar E, Hinojosa M, Loviscek M, Pellegrine $C$, et al. The impact of laparoscopic anti-reflux surgery in patients with Barrett's esophagus. Surg Endosc. 2014;28(12):327984. https://doi.org/10.1007/s00464-014-3601-z 
7. Humphries LA, Hernandez JM, Clark W, Luberice K, Ross SB, Rosemurgy AS. Causes of dissatisfaction after laparoscopic fundoplication: the impact of new symptoms, recurrent symptoms, and the patient experience. Surg Endosc. 2013;27(5):1537-45. https://doi.org/10.1007/s00464-012-2611-y

8. PRISMA (Preferred Reporting Items for Systematic Reviews and Meta-Analyses) - Transparent reporting of systematic reviews and meta-analyses [Internet]. [cited 2019 May 17]; Available from: http://www.prisma-statement.org.

9. Ouzzani M, Hammady $H$, Fedorowicz Z, Elmagarmid A. Rayyan: a web and mobile app for systematic reviews. Syst Rev. 2016;5(1):210. https://doi.org/10.1186/s13643-016-0384-4

10. Chan K, Liu G, Miller L, Ma C, Xu W, Schlachta CM, et al. Lack of correlation between a self-administered subjective GERD questionnaire and pathologic GERD diagnosed by 24-h esophageal pH monitoring. J Gastrointest Surg. 2010;14(3):42736. https://doi.org/10.1007/s11605-009-1137-7

11. de Bortoli N, Martinucci I, Savarino E, Bellini M, Bredenoord AJ, Franchi R, et al. Proton pump inhibitor responders who are not confirmed as GERD patients with impedance and $\mathrm{pH}$ monitoring: who are they? Neurogastroenterol Motil. 2014;26(1):28-35. https://doi.org/10.1111/nmo.12221

12. Masiak W, Wallner G, Wallner J, Pedowski T, Solecki M. Combined esophageal multichannel intraluminal impedance and $\mathrm{pH}$ monitoring ( $\mathrm{MII}-\mathrm{pH})$ in the diagnostics and treatment of gastroesophageal reflux disease and its complications. Pol Przegl Chir. 2011;83(9):488-96. https://doi.org/10.2478/ v10035-011-0076-7

13. Bello B, Zoccali M, Gullo R, Allaix ME, Herbella FA, Gasparaitis $A$, et al. Gastroesophageal reflux disease and antireflux surgerywhat is the proper preoperative work-up? J Gastrointest Surg. 2013;17(1):14-20. https://doi.org/10.1007/s11605-012-2057-5

14. Pugliese D, Mauro A, Consonni D, Bravi I, Tenca A, Elvevi A, et al. $\mathrm{pH}$ impedance vs. traditional $\mathrm{pH}$ monitoring in clinical practice: an outcome study. J Gastroenterol. 2016;51(2):130-7. https://doi.org/10.1007/s00535-015-1090-z

15. Friedman M, Hamilton C, Samuelson CG, Kelley K, Taylor $\mathrm{R}$, Darling $\mathrm{R}$, et al. The value of routine $\mathrm{pH}$ monitoring in the diagnosis and treatment of laryngopharyngeal reflux. Otolaryngol Head Neck Surg. 2012;146(6):952-8. https://doi. org/10.1177/0194599812436952
16. Hatlebakk JG, Zerbib F, des Varannes SB, Attwood SE, Ell C, Fiocca R, et al. Gastroesophageal acid reflux control 5 years after antireflux surgery, compared with long-term esomeprazole therapy. Clin Gastroenterol Hepatol. 2016;14(5):678- 85.e3. https://doi.org/10.1016/j.cgh.2015.07.025

17. Jasper D, Freitas-Queiroz N, Hollenstein M, Misselwitz B, Layer $P$, Navarro-Rodriguez T, et al. Prolonged measurement improves the assessment of the barrier function of the esophago-gastric junction by high-resolution manometry. Neurogastroenterol Motil. 2017;29(2). https://doi.org/10.1111/nmo.12925

18. Patcharatrakul T, Gonlachanvit S. Gastroesophageal reflux symptoms in typical and atypical GERD: roles of gastroesophageal acid refluxes and esophageal motility. J Gastroenterol Hepatol. 2014;29(2):284-90. https://doi.org/10.1111/jgh.12347

19. Ciriza-de-los-Ríos C, Canga-Rodríguez-Valcárcel F, Castel-deLucas I, Lora-Pablos D, de-la-Cruz-Bértolo J, Castellano-Tortajada G. How useful is esophageal high resolution manometry in diagnosing gastroesophageal junction disruption: causes affecting this disruption and its relationship with manometric alterations and gastroesophageal reflux. Rev Esp Enferm Dig. 2014;106(1):22-9. https://doi.org/10.4321/s113001082014000100004

20. Fornari F, Callegari-Jacques SM, Dantas RO, Scarsi AL, Ruas LO, Barros SG. Obese patients have stronger peristalsis and increased acid exposure in the esophagus. Dig Dis Sci. 2011;56(5):1420-6. https://doi.org/10.1007/s10620010-1454-4

21. Tolone S, de Bortoli N, Marabotto E, de Cassan C, Bodini G, Roman S, et al. Esophagogastric junction contractility for clinical assessment in patients with GERD: a real added value? Neurogastroenterol Motil. 2015;27(10):1423-31. 1 https:// doi.org/0.1111/nmo.12638

22. Broeders JA, Roks DJ, Draaisma WA, Vlek AL, Hazebroek EJ, Broeders IA, et al. Predictors of objectively identified recurrent reflux after primary Nissen fundoplication. Br J Surg. 2011;98(5):673-9. https://doi.org/10.1002/bjs.7411

23. Laurino Neto RM, Herbella FAM, Zugman A, Velanovich $V$, Montera B, Schlottmann F, et al. Minor psychiatric disorders and objective diagnosis of gastroesophageal reflux disease. Surg Endosc. 2019;33(12):4116-21. https://doi.org/10.1007/ s00464-019-06716-y 